\title{
Advanced Methods of Web Learning
}

\author{
Athanasios Drigas, Leyteris Koukianakis, and Yannis Papagerasimou
}

\author{
NCSR 'Demokritos', \\ Institute of Informatics and Telecommunications, \\ Net Media Lab, \\ Agia Paraskevi, 153 10, Athens, Greece \\ \{dr, kouk, ypapa\} @imm. demokritos.gr
}

\begin{abstract}
The exploitation of contemporary Information and Communication Technologies (ICTs) in the design process of advanced e-learning methods and systems is only one indispensable factor that needs to be addressed, considering that the principle need of students nowadays is the easy and straightforward access to educational material. In addition, the rapid technological evolution and the unceasing invasion of new technologies in the market, renders older technologies obsolete after only a short lifetime. Taking this into account, it becomes apparent that the cognitive material is affected in numerous ways and that the need to dynamically upgrade it is absolutely necessary in order for it to be constantly up to date and to follow closely the technological developments. Bearing in mind the two aforementioned factors, this paper presents an advanced educative web learning platform, which conforms to the above mentioned needs of contemporary education and students and learners in general.
\end{abstract}

Keywords: web learning, syllabus upgrade, cognitive material.

\section{Introduction}

The advance of the Internet and Information and Communication Technologies affects modern every-day life to a great extent and education is no exception. This advance, combined with the popularity of the Internet among users has led to the exploitation of ICTs by network engineers towards the integration of ICTs and the Internet with traditional teaching-learning methods. This integration has led to what is commonly known as e-learning or web learning. [1], [2].

Web learning (or e-learning) is the result of the advance of the Internet and the ICTs. It has completely changed education, the delivery of knowledge as well as the role of school. Web learning provides the opportunity to the user for distant learning through the Internet with multimedia means such as text, images, audio and video. [3], [4].

Furthermore, in recent years the development of web learning has been increasing rapidly. Due to this context, the subject of e-learning and its specifications and management have been widely studied. These include the authoring standards [5], the e-content [6], the e-content development and management [7], virtual classroom educational methods [8], [9], methodologies to improve the interoperability of the educational content [10], classification-evaluation of the e-student educational level and learning difficulties. 
Based on the above and aiming at creating a modern environment using user-friendly e-content, a special advanced web learning system was designed and developed for the dynamically adaptable education of students, based on a flexible-interoperable scheme of assistive informative and communicative tools and services. [11], [12], [13], [14], [15]

This web learning system was developed within the research activities and framework of Net Media Lab of N.C.S.R. 'Demokritos' and was based on the following facts. Firstly, education in general requires the dynamical adaptation of the syllabus. It is one of the most important features in an e-learning environment, whether it is about synchronous or asynchronous means of teaching-learning. In addition, it was established that the products of the market do not possess an embedded system that provides the opportunity for online operation and collaboration of the Instructors' Team, which dynamically reforms the syllabus.

\section{An Introduction to the Web Learning System}

This web learning system introduces an innovative method for the reformation and upgrade of the syllabus as well as for the methodology of the educative content structure. The electronic environment is basically the medium for the disposition, modeling and adaptation of the syllabus. The implementation of this method will bring the continuous dynamical upgrade of the syllabus content according to the technological evolution and the market and social needs. More particularly, in order to achieve this reformation and upgrade of the syllabus as well as its continuous feeding based on the technology evolution and the special needs of contemporary society, the following tasks must be undertaken:

\subsection{Continuous Upgrade of the Syllabus}

A considerable quantity of products and technologies are rendered obsolete due to the rapid technological advances, even in the course of one year. The capabilities of the informative and communicative mediums of the Internet render them very powerful supportive tools for the teaching procedure and methodology. Hence, it becomes more than apparent that the syllabus, which consists of text, audio, images and video must be dynamically reformed and adapted to the contemporary technological developments on an annual basis through a certain innovative procedure. This means that an A\% of the syllabus remains static, while the remaining B\% is dynamically reformed. By reformation we mean incorporation of new cognitive material in the already existing cognitive material rather than replacement. On the one hand, the stable A\% represents basic theory knowledge and indispensable cognitive background. On the other hand, the variable $\mathrm{B} \%$ represents the cognitive material that will be reformed by a special team of instructors - authors, in such a way in order to cover in full the new knowledge (techniques, products, methodologies) that have been developed in the meantime, satisfying hence, the needs of the market each time. The definition of these percentages (A \% and $\mathrm{B} \%$ ) resulted from a detailed research of the market needs and are decided by the aforementioned special team of instructors - authors. The results showed that the B percentage, which is dynamically reformed, ranges between 25$30 \%$ maximum. 
Based on the results of the detailed research of the market needs the percentages (A $\%$ and $\mathrm{B} \%$ ) were applied to the entire syllabus. This resulted in the gradual upgrade of students' education through an up to date and innovative procedure-methodology. This way, the continuous (annual) update of the instructed material is achieved, according to the rapid developments in the technological, social, pedagogical and geopolitical fields. Following closely the technological developments (products, techniques), which have the potential to drastically change the cognitive content of the educational material even within a year, gives the opportunity to new students to acquire indispensable up to date knowledge about new products and technical solutions, which will continuously upgrade their skills and will render them competitive members of the society and the market field.

\subsection{The Authors Group}

It was essential to the progress of the project to form a group of authors, allocated within the Greek borders and which will be responsible for the modeling and reforming of the syllabus. This context contributes to the redefining of the authors'instructors' role as they participate actively in the modeling and reformation of the syllabus' content as members of a forum. With this context in mind the following tasks were undertaken: Firstly, a forum that is composed of authors-instructors and members of scientific institutions, for the conveyance of knowledge and know how was created with the support of network technology. Secondly, collaboration between the authors-instructors' team, the industry and the scientific institutions through the aforementioned forum was initiated for the up to date informing and knowledge of new products and technologies. This forum contributes to the improvement of the conveyance of information and knowledge to and from the industry, the teachersinstructors and the students. Through specific actions, the forum informs the aforementioned interested parties about new products, their prices and availability. In addition, this program contributes to the upgrade of the quality of the educative work not only with the use of innovative methods but also with the support of the authorinstructor with newly updated educative material and electronic aids. Towards this direction, suitable educative material for the basic education and distance training through the Internet was produced and presented through the Web and a multi-subject database was created on the Web, which contains an electronic catalogue for new products, a terminology dictionary and a bibliography reference.

\section{Web Learning Platform Presentation}

The tools and services that were used for the design of this web learning platform are distinguished into two groups: the 'informative' and the 'communicative' tools. On the one hand, the 'informative' tools are divided into the purely informative and the supportive tools and include services related to the educational material and its presentation. On the other hand, the 'communicative' tools are divided into real time and non real time tools and include services that allow the communication of the different user groups. In particular, the 'informative' tools comprise the following: web directory, courses material, courses schedule, glossaries, references, video and audio 
lectures, calendar-events, news, announcements and mailing lists. On the other hand, the 'supportive' tools comprise: exercises, examples and tests. As far as the communicative tools are concerned, in the 'real time' category the tools comprise: video and audio conference, instant messaging and chat. One the other hand, the 'non real time' tools comprise: discussion forums, message boxes, e-mail, video and audio e-mail.

The use of the communicative tools ensures the online collaboration and communication of the group of instructors-authors. This instructors-authors team uses the aforementioned tools, composes and uploads the dynamically adapted and reformed part of the syllabus (B \%), which is added to the already existing syllabus. Hence, the instructors-teachers of the e-environment have access to the updated syllabus without having to get implicated in the reformation process. This web learning platform relates and manages the tools to the educational material courses according to the specific user level permissions. The e-environment distinguishes four user levels, namely, administrator, instructor-teacher/author, student and unauthorized user, each of which possesses a different role in the system as well as different supporting tools. Each of them interacts with the other through the relative tools of each level.

\subsection{Administrative Tools}

The role of the administrator is to coordinate and manage the web learning platform through the use of the administrative tools. The administrator determines which user level-group has the permission to use the corresponding tools and services. Moreover, the administrator can communicate with the instructor in order to be kept informed about the progress of the instructors' courses.

The environment provides administrative tools that are divided into three groups as follows: management of general services, management of 'informative' services and management of 'communicative' services (Fig. 1). The transactions executed in each group concern the retrieval, insertion and update of the corresponding data. In particular, the "general services" group of tools includes management of the data structures of: news, events, announcements and the users. The management of the 'informative' services is of major importance, as it enables the administrator to determine the type and the number of seminars, classes, courses, instructors and students. The 'communicative services' group includes services through which the administrator can manage: announcements, the e-library of courses and the discussion forum. Moreover, through certain services the administrator communicates with each of the instructors separately.

\subsection{Instructor Tools}

This particular web learning platform distinguishes two kinds of instructors: the instructor-author, who is a member of the authors' group, which is responsible for the dynamical adaptation and reformation of the syllabus and the instructor-teacher, whose only responsibility is the teaching of the courses. Normally, the instructorauthor can be an instructor-teacher simultaneously, while the opposite is rare. 


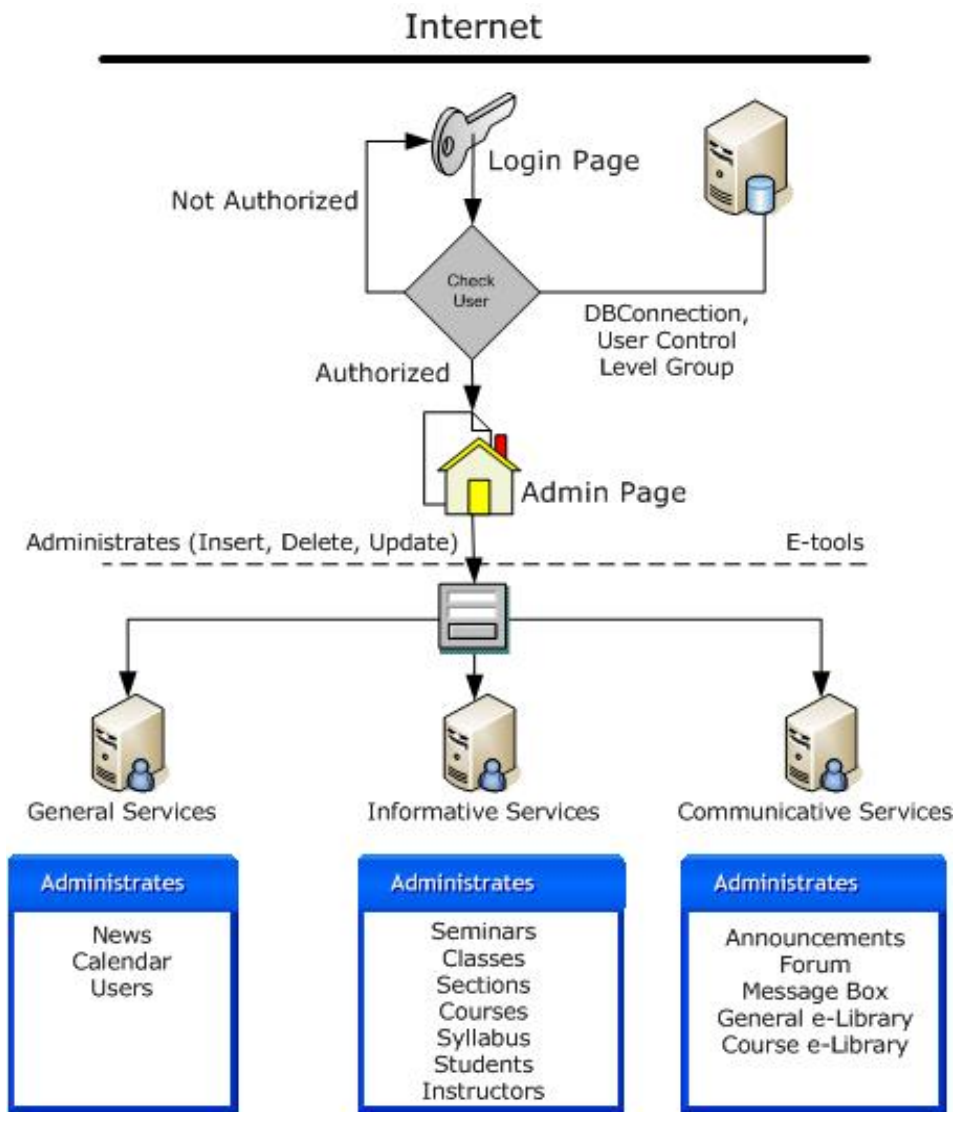

Fig. 1. Administrative tools

The instructors-authors, who form the group of authors determine, reform and adapt the educational material and also determine the way that the material will be presented to the instructor-teacher, the students and to the entire Internet community. Their communication and tasks take place online through the use of the various communicative tools such as discussion forums. On the other hand, the instructorsteachers access the e-content that is uploaded by the instructors-authors and use it for the teaching of the courses.

In addition, there is the possibility of communication between the instructorteacher and the students, which aims at the resolution of questions. The provided tools help the instructor to organize the course in a way that will help the students in the direct comprehension of the courses (Fig. 2). Finally the tools enable the instructorteacher to conceive the learning weaknesses of his/her students, and to select the education process of each course. In particular, the instructors' tools can be divided into three groups as follows. 


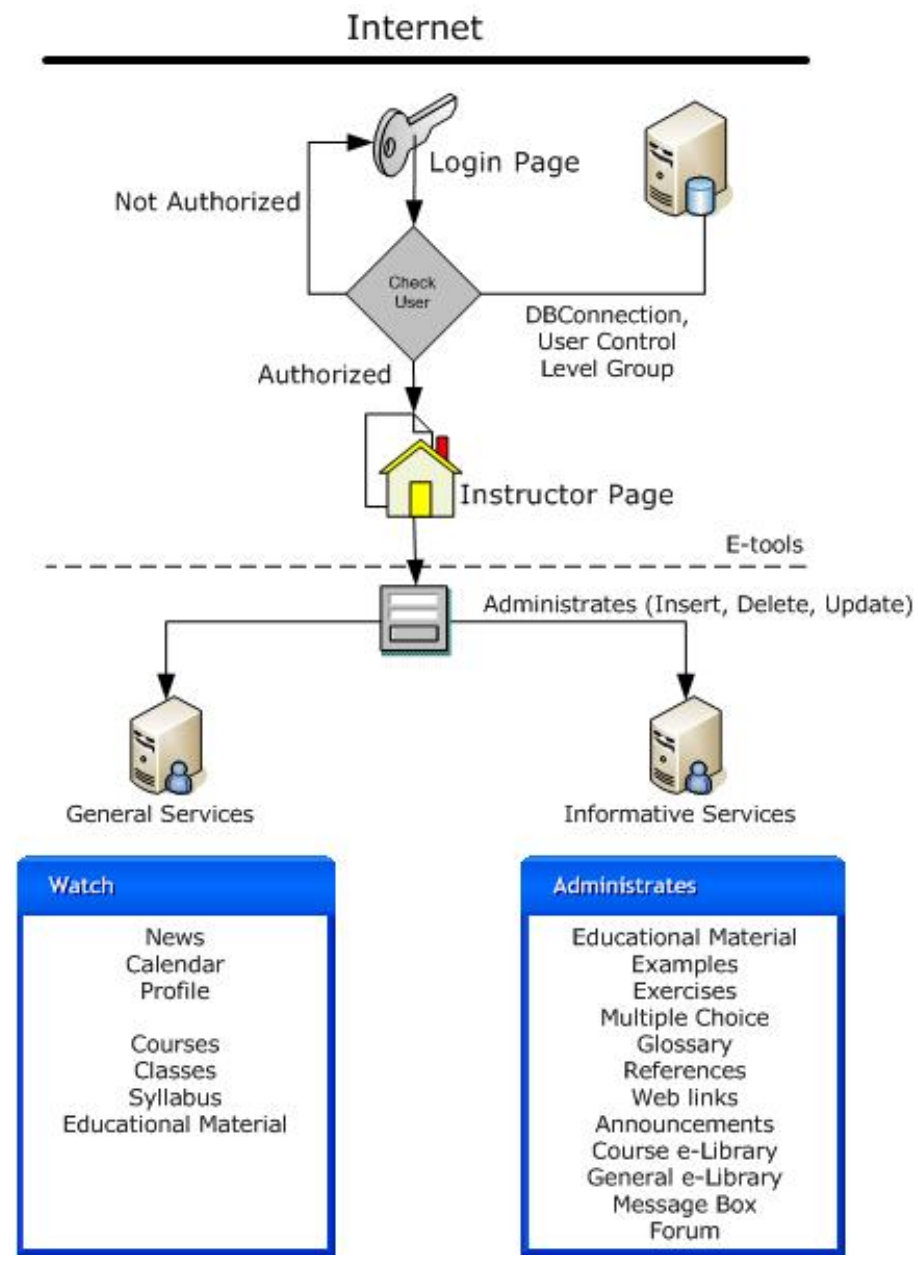

Fig. 2. Instructor tools

The first group includes general services such as management tools of news, events, courses retrieval/search, the syllabus and the educational material. The second group includes tools that allow the fast access to the already consulting material such as: examples, exercises, tests, glossary, references, web links, the e-library, announcements, solutions of exercises and discussions between students and instructors. Finally, the third and more basic group of the instructors' services is the one that enables the instructors-authors to reform, adapt and manage the educational material (chapters, sub-chapters, paragraphs) and the accompanying material (examples, exercises, tests, glossary, references, web links, e-library, announcements). In addition, there is the management of the discussions between the instructors-teachers and their students for the answer of questions, the discussions with the students on the practical application of the educational subjects and the message box from personal communication with the administrator. 


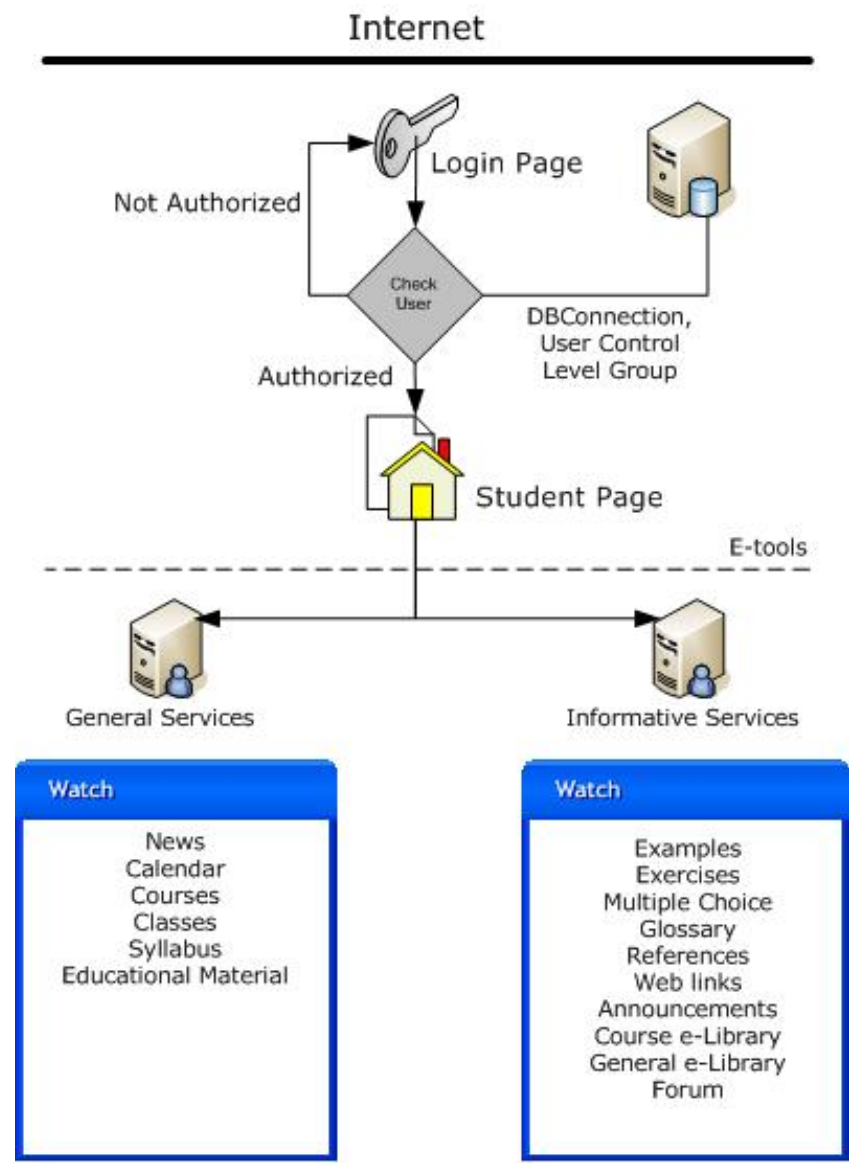

Fig. 3. Student tools

\subsection{Student Tools}

Students have access to all the information and services, at all times. This way, continuous access to knowledge and consequently, better course comprehension is achieved (Fig. 3). Students determine the successful development of the seminars and courses. Moreover, the students read the educational material registered by the team of instructors-authors and communicate and pose questions to the instructor-teacher and they are the ones that try to resolve exercises or questions of multiple choices.

Student tools are divided into two groups of tools. Firstly, into general services, which allow the fast access to: news, events, courses, the syllabus and educational material. The second group includes tools that allow the fast access to the consulting material: examples, exercises, solutions of exercises, multiple choices, glossary, references, web links, e-library. What is important in this group is the possibility of communication with the instructor-teacher via the discussion forums. Moreover, the 
student has access to the answers of his/her questions and also has the opportunity to discuss with the instructor, the practical application of the theoretical subjects.

\subsection{Unauthorized User}

This level provides the possibility to the unauthorized user - visitor to browse through the e-content of the courses of the web learning platform. The innovation of this level lies in the fact that the visitor can have access to the consulting material for each course, but also to the discussion forums. Finally, this level follows the standard 'knowledge-access for all', giving the permission to the random visitor to obtain the knowledge of his/her object of interest.

\section{Conclusions}

Concluding, it is easy to realize the benefits of applying dynamical adaptation functions for the syllabus for all the interested users. First and foremost, there was the undoubted upgrade of the cognitive standard of both the teachers and the students. The continuous reformation of the syllabus brings up to date cognitive material to the students rendering them more competitive and enhancing their knowledge and skills according to the rapidly accelerating technological and market developments. In addition, the role of the instructor-author is upgraded to a great extent rendering him/her an active member of the education society as (s)he is now the molder of the educative program. Finally, the social role and the operation framework of schools changes drastically and there is an overall improvement of the educative results. The didactic methodology in the classroom changes as well as the classroom itself as there is the possibility for certain students to attend classes from a distance (distance learning). These changes and upgrades take place through the prism of globalization and in the following units: new pedagogical teaching techniques, social education and the role of the citizen in Europe and finally, European education.

\section{References}

1. Tavangarian, D., Leypold, M.E., Nölting, K., Röser, M., Voigt, D.: Is E-Learning the Solution for Individual Learning? Electronic Journal of E-Learning (EJEL) 2(2) (2004)

2. Colace, F., DeSanto, M., Vento, M.: Evaluating Online Learning Platforms: A Case Study. In: 36th Hawaii International Conference on System Sciences. IEEE Press, Los Alamitos (2003)

3. Humar, I., Pustisek, M., Bester, J.: Developing Dynamic Educational Material with Integrated Mathematical Notation for Web-Based E-Learning System. In: 33rd ASEE/IEEE Frontiers in Education Conference, pp. T3F19-24. IEEE Press, Los Alamitos (2003)

4. Drigas, A.S., Koukianakis, L.: A Modular Environment for E-Learning and E-Psychology Applications. In: 4th WSEAS International Conference on Applied Informatics and Communications, pp. 2062-2067 (2004)

5. Casadei, G., Magnani, M.: Assessment Strategies of an Intelligent Learning Management System. In: International Conference on Simulation and Multimedia in Engineering Education (2003) 
6. Nabeth, T., Angehrn, A.A., Balakrishnan, R.: Integrating Context in E-Learning Systems Design. In: 4th IEEE International Conference on Advanced Learning Technologies, pp. 355-359. IEEE Press, Los Alamitos (2004)

7. Drigas, A.S., Vrettaros, J.: An Intelligent Tool for Building E-Learning Content-Material Using Natural Language in Digital Libraries. In: WSEAS Transactions on Information Science and Applications, pp. 1197-1205 (2004)

8. Hoyer, H., Jochheim, A., Rohrig, C., Bischoff, A.: A Multi-User Virtual-Reality Environment for a Tele-Operated Laboratory. In: IEEE Transactions on Education, pp. 121-126. IEEE Press, Los Alamitos (2004)

9. Geoffroy, F., Aïmeur, E., Gillet, D.: A Virtual Assistant for Web-Based Training in Engineering Education. In: Cerri, S.A., Gouardéres, G., Paraguaçu, F. (eds.) ITS 2002. LNCS, vol. 2363, pp. 301-310. Springer, Heidelberg (2002)

10. Ternier, S., Duval, E., Neven, F.: Using a P2P Architecture to Provide Interoperability Between Learning Objects. In: World Conference on Educational Multimedia, Hypermedia, and Telecommunications, pp. 148-151 (2003)

11. Graf, S., List, B.: An Evaluation of Open Source E-Learning Platforms Stressing Adaptation Issues. In: 5th IEEE International Conference on Advanced Learning Technologies, pp. 163-165. IEEE Press, Washington (2005)

12. Fedák, V., Bauer, P., Hajek, V., Weiss, H., Davat, B., Manias, S., Nagy, I., Korondi, P., Miksiewicz, R., Van Duijsen, P., Smékal, P.: Interactive E-Learning in Electrical Engineering. In: International Conference on Electrical Drives and Power Electronics, pp. 368373 (2003)

13. Drofenik, U., Kolar, J., Van Duijsen, P., Bauer, P.: New Web-Based Interactive ELearning in Power Electronics and Electrical Machines. In: Industry Applications Conference, 36th IAS Annual Meeting. IEEE Press, Los Alamitos (2001)

14. Kluj, S.: The Potential of Computer Aided Learning and its Impact on Marine Engineering Education and Training. In: 3rd Global Congress on Engineering Education, pp. 342-344 (2002)

15. Cooper, M.: Remote Controlled Teaching Experiments in Science and Engineering Subjects, Accessible over the World-Wide-Web: The PEARL Project. In: World Conference on Educational Multimedia, Hypermedia and Telecommunications, pp. 1296-1297 (2000) 